\title{
Clinician's Corner
}

\section{Identical twins with microcytosis}

\author{
Kathleen Moolman MD FRCPC ${ }^{1}$, Victoria Price MBChB MSc FRCPC ${ }^{2}$, Robyn McLaughlin MD FRCPC ${ }^{3}$ \\ ${ }^{1}$ Division of General Pediatrics, Royal University Hospital, Saskatoon, Canada; ${ }^{2}$ Division of Hematology and \\ Oncology, IWK Health Centre, Halifax, Nova Scotia; ${ }^{3}$ Division of General Pediatrics, IWK Health Centre, Halifax, \\ Nova Scotia \\ Correspondence: Robyn McLaughlin, IWK Health Centre, 5850/5980 University Ave, Halifax, Nova Scotia B3K 6 R8. \\ Telephone 902470 8222, fax 902470 7761, e-mail Robyn.McLaughlin@iwk.nshealth.ca \\ Work originated at the IWK Health Center, Halifax, NS, Canada.
}

Twin females were born at 27 weeks gestation after a pregnancy complicated by twin-twin transfusion. Due to the family's relocation, at 11 months of age, follow-up assessment occurred at our centre. At that time their only medications were iron $(1.8 \mathrm{mg} / \mathrm{kg} /$ day $)$ for a history of anemia of prematurity and Vitamin D supplementation. Newborn screening for hemoglobinopathies was negative for both girls.

Repeat laboratory investigations on both showed a microcytosis with normal ferritin and zinc protoporphyrin. Hb electrophoresis results are shown in Table 1.

The family is of Lebanese descent. The twins were presumed to be monozygotic. Medical records described mono-amniotic di-chorionic twins and this was further supported by the history of twin-twin transfusion. However, only one twin's $\mathrm{HgbA}_{2}$ was elevated. Due to the discordant results, further investigations were required.
Table 1. Hematologic results

\begin{tabular}{lcc}
\hline Test (normal range) & Twin A & Twin B \\
\hline Red blood cell (3.97-5.01) & 5.06 & 5.07 \\
Hemoglobin (102-127) & 116 & 117 \\
Hematocrit (0.309-0.379) & 0.353 & 0.356 \\
MCV (71.3-82.6) & 69.8 & 70.2 \\
MCH (23.2-27.5) & 22.9 & 23.1 \\
Hemoglobin A (>80\%) & 81.9 & 81.8 \\
Hemoglobin A2 (1.8-3.6\%) & 2 & 3.9 \\
Hemoglobin F (<4\%) & 3.9 & 2.1 \\
\hline
\end{tabular}

$\mathrm{MCV}$, mean corpusular volume; $\mathrm{MCH}$, mean corpusular hemoglobin 


\section{DIAGNOSIS: THALASSEMIA TRAITS}

Beta globin genes are found on chromosome 11. Each chromosome 11 carries one beta gene, with two copies in total. Deletion or mutation of a single copy causes microcytosis and a mild anemia known as beta-thalassemia trait. Beta-thalassemia trait will alter the relative amount of types of hemoglobin produced, causing an elevation in hemoglobin $(\mathrm{Hb}) \mathrm{A}_{2}$ detectable on electrophoresis. Twin B had microcytosis, without evidence of iron deficiency, and an elevated $\mathrm{Hb} \mathrm{A}_{2}$. Accordingly, the diagnosis was consistent with beta-thalassemia trait, and as per our standard practice, genetic testing was not required.

Alpha globin genes are found on chromosome 16. Each chromosome 16 carries two alpha genes, with four copies in total. Deletion of one or two copies of the alpha gene causes microcytosis and possibly mild anemia. This is called alpha-thalassemia trait. Alpha-thalassemia trait does not affect the relative proportions of the types of hemoglobin produced. Therefore, it is undetectable on electrophoresis and can only be diagnosed by genetic testing. Twin A had a microcytosis, without evidence of iron deficiency, and without an elevation in $\mathrm{Hb} \mathrm{A}_{2}$. Alpha-thalassemia trait was suspected. As per standard practice, testing for alpha gene deletions alone would be requested in such a case.

Given the different electrophoresis results in apparently identical children, genetic testing of both alpha and beta genes was arranged, which clarified the diagnosis. Both twins had c.95+2_95+6del mutation of the HBA2 gene (alpha-thalassemia trait/minima) and c. $92+6 \mathrm{~T}>\mathrm{C}$ mutation on the $\mathrm{HBB}$ gene (beta-thalassemia trait/minor).

\section{DISCUSSION}

Though asymptomatic, identification of individuals with thalassemia trait is important. First, before diagnosis patients are often incorrectly diagnosed with iron deficiency and prescribed unnecessary iron. Second, it is important to identify individuals with thalassemia trait for their future conception counselling. Additionally, when a child is identified with thalassemia trait, testing of the parents is strongly recommended as there may be potential of subsequent offspring having thalassemia disease (1).

If twin A had presented as a singleton, she would have had testing for, and subsequently been diagnosed with, alpha-thalassemia trait. Her parents then would have been screened for alpha gene mutations only. If twin B had presented as a singleton, she would have been diagnosed with beta-thalassemia trait and no alpha gene testing would have been arranged. Parents would have been screened with $\mathrm{Hb}$ electrophoresis, to identify beta-thalassemia trait. Coinheritance of alpha and beta traits was identified only due to divergent results in identical twins, and would have been missed by our standard testing algorithm.

The proportion of cases with coinherited alpha and beta-thalassemia is not documented. A small study from Iran found up to $65 \%$ of beta-thalassemia patients had coinherited alpha-thalassemia (2). Rates of coinheritance in Canada are unknown. Also, there is discrepancy in the literature about the effect of coinheritance on $\mathrm{Hb} \mathrm{A}_{2}$. Our case demonstrates the variability of $\mathrm{Hb} \mathrm{A}_{2}$ in coinherited alpha/beta-thalassemia trait, as one twin had a normal hemoglobin $\mathrm{A}_{2}$ and one had elevated $\mathrm{Hb} \mathrm{A}_{2}$. The discrepancy in $\mathrm{Hb}_{2}$ between the twins in this case, with identical deletions, demonstrates the need to reassess our current diagnostic algorithms to prevent missed diagnoses, and missed opportunities for accurate preconception counselling.

\section{CLINICAL PEARLS}

1. Alpha- and beta-thalassemia trait may coexist, and can make diagnosis difficult. Presence of beta-thalassemia may be detected on electrophoresis, leading to premature completion of diagnostic workup, subsequently missing alpha-thalassemia trait.

2. Coinheritance of alpha- and beta-thalassemia trait may mask the elevation of hemoglobin A2 expected in beta-thalassemia trait subsequently missing beta-thalassemia trait.

3. Newborn screening may identify some forms of thalassemia trait and disease, however, normal newborn screening does not exclude the presence of thalassemia traits.

\section{References}

1. Taher A, Musallam K, Domenica Cappellini M. 2013. Guidelines for the management of non transfusion dependent thalassaemia. Thalassaemia International Federation Publication No. 19.

2. Alizadeh S, Bavarsad MS, Dorgalaleh A. 2014. Frequency of beta-thalassemia or beta-hemoglobinopathy carriers simultaneously affected with alpha-thalassemia in Iran. Clin Lab. 60(6):941-9. 